\title{
Undergraduate Facilitators' Perspectives of Engineering Summer Programs
}

\section{Ms. Rachel Jannette McFalls, Mississippi State University}

Rachel is a first year masters student in Aerospace Engineering at Mississippi State University. She graduated from Mississippi State University with a B.S. in Aerospace Engineering in May 2014. Her current research interests include K-12 STEM education, first-year engineering, retention, transition, and engineering identity.

\section{Ms. Carla Danielle Grimes, Mississippi State University}

Danielle is a first year doctoral student in Biomedical Engineering at Mississippi State University. She graduated Cum Laude from Mississippi State University with a Biological Engineering bachelor's degree in May 2014, and Danielle was inducted into the Bagley College of Engineering Student Hall of Fame in April 2014. Her research interests include females in engineering and K-12 STEM education.

Dr. M. Jean Mohammadi-Aragh, Mississippi State University

Dr. M. Jean Mohammadi-Aragh is an assistant research professor with a joint appointment in the Bagley College of Engineering dean's office and the Department of Electrical and Computer Engineering at Mississippi State University. Through her role in the Hearin Engineering First-year Experiences (EFX) Program, she is assessing the college's current first-year engineering efforts, conducting rigorous engineering education research to improve first-year experiences, and promoting the adoption of evidence-based instructional practices. In addition to research in first year engineering, Dr. Mohammadi-Aragh investigates technology-supported classroom learning and using scientific visualization to improve understanding of complex phenomena. She earned her Ph.D. (2013) in Engineering Education from Virginia Tech, and both her M.S. (2004) and B.S. (2002) in Computer Engineering from Mississippi State. In 2013, Dr. Mohammadi-Aragh was honored as a promising new engineering education researcher when she was selected as an ASEE Educational Research and Methods Division Apprentice Faculty.

\section{Dr. Rani W. Sullivan, Mississippi State University}

Rani Warsi Sullivan is an associate professor of aerospace engineering at Mississippi State University. She received her PhD, MS, and BS in Aerospace Engineering from Mississippi State University. Dr. Sullivan has teaching and research interests in the area of engineering mechanics, mechanical vibrations, aerospace structures and polymer viscoelasticity. She maintains a strong interest in developing methods to increase experiential education. Her current research involves the characterization of the time-dependent deformation of polymer matrix nanocomposites and the use of fiber optic strain sensing for development of an in-flight structural health monitoring system for an all-composite unmanned aerial vehicle.

\section{Dr. James Warnock, Mississippi State University}

James Warnock is the Interim Associate Dean for Undergraduate Studies in the Bagley College of Engineering at Mississippi State University. His background is in biomedical engineering and he has been a big proponent of self-directed learning and active learning in his classes and was the first person to introduce problem-based learning in the department of agricultural and biological engineering at MSU. James is also the Adjunct Director for training and instruction in the professional services department at ABET. In this role, Warnock oversees the development, planning, production and implementation of the ABET Program Assessment Workshops, IDEAL and the assessment webinar series. He also directs activities related to the workshop facilitator training and professional development. 


\section{Undergraduate Facilitators' Perspectives of Engineering Summer Programs}

\section{Introduction}

Summer programs are often used by universities to recruit students into engineering by educating and inspiring them. Programs have various target audiences and objectives. For example, some programs are targeted at retaining incoming high-achieving high school students in engineering programs (e.g., ${ }^{1-2}$ ). Some programs provide academic success coaching and supplementary training in fundamental skills (e.g., ${ }^{3-4}$ ). Other programs are designed in conjunction with more general outreach efforts to entice K-12 students into applying to engineering programs (e.g., ${ }^{5}$ ). Along with a description of the program design, authors often report that students who attend an engineering summer program are retained in undergraduate engineering programs at higher rates than students who did not participate in a summer program. While these claims are often supported with limited performance data ${ }^{6}$, there is evidence that summer programs can impact students' academic motivation ${ }^{7}$. With the increasing call for engineers, summer programs are a popular method for universities to recruit high school students.

Along with the increased interest in summer programs comes the need for more staff for such programs, which has created an opportunity for advanced undergraduate students to design and facilitate summer programs. This paper examines the experiences of two undergraduate facilitators of two different engineering summer programs, a perspective that is missing from current literature. This work is a first step towards better understanding how undergraduates can effectively support staffing needs for engineering summer programs. The two experiences described herein are exemplars of the roles that advanced undergraduate students can serve in support of summer programs. By analyzing the perceived success of the programs with respect to the different program goals and motivations, we provide tricks of the trade for both undergraduate and graduate students who would like to be or are already involved in planning or leading an engineering summer program. This study was designed to specifically answer these two research questions (RQ):

RQ1) How can undergraduate students effectively facilitate engineering summer programs for $\mathrm{K}-12$ students?

\section{RQ2) How can the experience for an undergraduate student facilitating engineering} summer programs be improved?

To answer our research questions, we employed a qualitative, autoethnographic-inspired approach. Autoethnography is a qualitative research method that systematically describes and analyzes personal experiences and the context or culture where the experiences occur ${ }^{8}$. It is a method for examining personal experiences analytically. The two student authors of this paper are the facilitators whose experiences are described and analyzed. Previously in engineering education literature, personal experiences have been used to provide perspective on $\mathrm{PhD}$ student experiences ${ }^{9}$, examine the experience of married faculty in a single engineering department ${ }^{10}$, explain the balance of teaching, research, and service for tenure-track faculty ${ }^{11}$, and finally to 
provide perspective on being effective faculty members in the classroom ${ }^{12}$. Examining personal experiences is appropriate for our study because it helps to capture the untold perspective of undergraduate student facilitators. Importantly, the undergraduate student facilitator perspective can provide information to students who are interested in implementing similar programs at their own universities. Ultimately, the data and perspectives reported in this paper can lead to improvements for summer engineering programs, which will help promote the field of engineering to high school students across the country.

\section{Methods}

The facilitators chosen had both graduated from their undergraduate degrees the month before facilitating their programs. The first researcher had experience with her program because she had previously been a student in the program. The second researcher worked in the office that hosted several summer programs over the year, but in this paper, she focuses on her experiences with the co-educational program for high school students.

Consistent with our research design, the authors and facilitators collaboratively developed a series of six short-answer prompts (A-F) to answer our two research questions. The first prompt related to understanding the overarching goals for each program (A). Three prompts focused on facilitation and logistic issues related to the first research question (RQ1) (B-D). Two prompts focused on identifying ways to improve the experience for undergraduate facilitators related to the second research question (RQ2) (E-F).

A. What was the goal of your summer program?

B. How was the goal of the program achieved?

C. To what extent did you as an engineering undergraduate feel that the goal was achieved?

D. How did you get involved with the program?

E. Describe your experience facilitating your summer program and how it may or may not have impacted your engineering identity

F. What were some lessons learned while being a facilitator of the program?

Each prompt was answered independently. Responses were coded using the open coding methods outlined by Strauss and Corbin ${ }^{13}$. Coded responses were analyzed collaboratively by the authors to identify salient themes. When coding, the researchers took both of their individual interviews and coded keywords of each sentence then went back through the keywords and developed themes found throughout the paper. Once the researchers had individually coded and found their own themes, they came together to discuss common themes and codes. The researchers found three major themes in the interviews: the establishment of identity, development of community, and the recruitment of future engineers.

The remainder of this paper is organized as follows: sections 3-8 contain the results and discussion for each of the six prompts (A-F), section 9 contain tips and tricks aimed at helping future facilitators plan and implement summer programs, and section 10 contains our conclusions. 


\section{Overview of Programs and Goals - Understanding Overarching Goals}

This section focuses on Prompt A: What was the goal of your summer program?

The two programs had different objectives as was answered by Prompt A. One program was primarily geared towards recruiting students to a specific university. This summer engineering program focused on rising seniors from high schools across the country. Numerous students complete the application, which requires essays and letters of recommendation, but only the top students are accepted. In 2014, 10 students attended a three-week program which required them to stay in a campus dormitory, conduct research for their mentors, explore educational and research facilities, and get a taste of college life. Like real college students, the students in the program had many freedoms and responsibilities: getting to their lab to meet their mentors on time, organizing a group for lunch, meeting back up with the group later in the day for tours and other activities. The facilitators allowed ample time for the students to explore the campus and evolve their own ideas about college life. The facilitator described the program as follows:

The goal of the summer program is to recruit the best and brightest to [University Name Deleted] by offering them summer research opportunities in various engineering disciplines. I believe that a happy byproduct of [Program Name Deleted] is that the students that DO get recruited have a more established engineering identity and therefore are retained in engineering better than students on the traditional pathway. The second program was designed to inform high school students about the field of engineering and the various engineering disciplines. About 20 students who ranged between 15-17 years of age, were housed on campus in a residence hall. This co-educational program targeted high school students, and 2 male and 3 female counselors were rotated throughout the week so that the students were never unsupervised. The classroom was monitored by one engineering teacher and an undergraduate facilitator. Each day, the students were in the classroom from 9:00 am to 5:00 pm with a lunch break at noon in the university cafeteria. They would also take time during the class day to tour various engineering research buildings on campus, listen to speakers, and complete projects. After class, the counselors accompanied the students to their dorm room for a break, followed by various extracurricular activities (i.e. movies, games, kickball, etc.). The program lasted for seven days and required that the students give a presentation to their parents about information they learned throughout the camp. The facilitator described the program as follows:

[The purpose of the camp was] to inform students of the different types of engineering as well as expose them to the types of projects that engineers undertake. The students were also given the chance to meet professors and research leaders on campus to form connections for once they graduate college. Our program was simply for education and to help push people into the field of engineering. It was not a recruitment program for [University Name Deleted], but rather, it was recruitment for the engineering field. We hoped that by educating the students on engineering, they would feel more confident in choosing engineering as their college major. We wanted the field to seem more accessible while also explaining what is expected of engineers.

In this paper we differentiate the two programs by referring to their goals. In other words, we refer to the program that targets recruiting students to a specific university as the University 
program (UNIV) and the program that focuses more on broad information as the High School program (HS).

\section{Achieving Program Goals}

This section focuses on Prompt B: How was the goal of the program achieved? (Facilitation and logistic issues (RQ1)

Even though UNIV and HS had different goals, the processes for achieving program goals were similar for both programs. When the undergraduate facilitators were interviewed about their programs, they discussed how they used their camps to help develop the students' engineering identities, to create a sense of engineering community, and to educate and recruit the students into engineering programs.

The undergraduate facilitators designed the camps with the idea of creating future engineers and recognized that people must first identify with a field before choosing it as a major. Although the summer program participants had expressed an interest in an engineering field when they registered, the facilitators felt that they had to cement this interest and recruit the students into engineering. They achieved this by having the students learn engineering lessons and apply those lessons in a situated learning environment. One engineering program divided the students by their engineering interests and had them conduct research in the field of their choice under the guidance of a professor while the other program chose a field of engineering each day to study and do a hands-on classroom project. Both program facilitators evaluated the students' responses to the "new" types of engineering. The facilitators engaged in conversations with the students, and at the end of the week, all the students were asked with which type of engineering they most closely identified. The facilitators also found that their own identities were somewhat impacted by working with these students; both undergraduate facilitators realized they had a growing interest in education, specifically a strong interest in engineering education research.

The summer programs were also developed so that the students would form a sense of community. The students were housed together and oftentimes asked to engage in extracurricular activities in order to help them form closer bonds. The undergraduate facilitators spoke of trying to form a community with their students. One facilitator mentioned that she continues to maintain contact with some of the people who attended her program during the summer. All the students in both programs came into contact with faculty members and were encouraged to take business cards so that they would have a contact person if they chose to enroll in an engineering discipline at the hosting university. By accumulating these contact people, the students were able to form their own network within the university.

The facilitators also discussed the importance of recruiting the students into engineering by informing them of the opportunities in the various engineering fields. By conducting tours of different research facilities, the students were introduced to multidisciplinary engineering as well as real life applications of the lessons they had been learning during the week. One facilitator listed that after every tour she and the students discussed their tour experience; the facilitator noted the students' excitement and interest. The facilitators also ensured that the students were 
able to apply the lessons they were learning in class to real-world problems. Because engineering is an application-based discipline, the students needed to know that new ideas can build on each other.

\section{Extent to Which Goals Were Achieved}

This section focuses on Prompt C: To what extent did you as an engineering undergraduate feel that the goal was achieved? (Facilitation and logistic issues (RQ1)

Both facilitators believed that their program goals were well achieved, and one of the facilitators said that the "program succeeded better than ever before" (UNIV). The facilitators also discussed how they engaged the students within their programs, and they both believed that the communication with the students helped to meet the goals of the programs over the week.

The HS facilitator, however, mentioned that the program "did scare some of the students out of engineering" (HS) because of the intensity of the work that the students were expected to do. She also mentioned that if the students became frustrated with any project, they would reject that engineering major.

\section{Involvement with Program}

This section focuses on Prompt D: How did you get involved with the program? (Facilitation and logistic issues (RQ1))

To inform future undergraduate facilitators, the programs' facilitators were asked how they became involved with their programs. Both facilitators listed some sort of prior experience that provided them contacts for the job, which leads to the belief that undergraduates with a previously established connection in the engineering outreach community are more likely to be employed as facilitators.

The facilitator for the UNIV had previously been a participant in the UNIV program. She inquired with her former counselor and program host about coordinating the program for 2014. Her experience as a participant informed her experience as a facilitator; she understood the elements of a 'good' program experience and could work towards creating the best program possible by networking to find presenters and mitigating problems quickly.

The facilitator for the High School based program listed that she had previously been employed by the office hosting the camp and had worked as a program helper before being promoted to facilitator. Her knowledge of the office and programs allowed her a great amount of freedom when planning the daily activities.

\section{Impact on Engineering Identity}

This section focuses on Prompt E: Describe your experience facilitating your summer program and how it may or may not have impacted your engineering identity. (Ways to improve experience for undergraduate facilitators (RQ2)) 
Both of the facilitators have fairly well established engineering identities as they had finished their undergraduate degrees in engineering fields, and one facilitator went on to describe the various ways she had developed her engineering identity with her involvement in several different engineering societies. One of the facilitators said that she had a previously established engineering identity, but that she "found [herself] learning along with the students" (HS). Both of the facilitators discussed that although their engineering identities were already strongly formed, their involvement in the programs allowed them to start forming their identities in engineering education. Their experiences in the programs helped them to "investigate" (UNIV) engineering education and to become more "effective" (HS) as an engineering education researcher.

\section{Lessons Learned}

This section focuses on Prompt F: What were some lessons learned while being a facilitator of the program? (Ways to improve experience for undergraduate facilitators (RQ2))

The HS facilitator discussed how she learned the effectiveness of engineers in research as well as how often research within engineering is interdisciplinary. She also found that projects often require several different perspectives to arrive at the best solution. Due to the summer program, the facilitator also discussed how the experience as a facilitator allowed her to see potential areas for research in the future.

The UNIV facilitator discussed the need to be highly organized. She emphasized the need to plan ahead and to maintain order while planning events and speakers. The facilitator also said that it is better to plan everything early so that you have time to rearrange events if necessary.

\section{Improvement - Tips and Tricks}

Our results featured two programs that took different approaches to introducing high school students to engineering in college: college-focused and high school-focused. For the most part, the facilitators for the two programs had many similar experiences, providing a more unified set of suggestions for future programs. In some cases the opinions for areas of improvement differed, and that is noted in the description of the tip or trick. Tips and tricks focus on program planning (9.1-9.3), program implementation (9.4-9.6), and program assessment (9.7).

\subsection{Start Planning Early}

Both programs suggested that early planning (about two months before the event date) was necessary for a successful program. By contacting people early to start scheduling speakers, tours, and presentations, the facilitator was able to prevent scheduling conflicts with other camps and missed opportunities.

- Contact [the person in charge of making the camp happen] early.(UNIV)

- Start contacting department heads before the end of the school year. They tend to go on vacation after mid-May.(UNIV) 
- Potential speakers should be contacted about 1.5 months in advance and at the very least a month in advance.(HS)

- Contact the places you would like to tour prior to scheduling your speakers. The touring places typically have a much tighter schedule and are able to book you further in advance. $(H S)$ "

Similarly, making lists and gathering the necessary materials before the beginning of the camp allows the facilitators to be prepared for the large groups of students and makes everyone's jobs easier. "Make supply lists and stock the classroom at least a week in advance so that the instructor can note anything missing. Making a ton of last minute runs to a store is a waste of time.(HS)"

The UNIV facilitator found that having one single person with all of the information was best for executing planning details:

If you want something done right, do it yourself. Ordering dinners, reserving rooms, planning trips, etc was easier to do yourself first rather than it was to fix later. If multiple facilitators are involved in planning, it is very important to have a detailed implementation plan with clear roles for each facilitator.

\subsection{Provide Information to Camp Participants and Parents Early}

Both facilitators noted that it was very important to provide the students and parents with as much information as possible ahead of time. The UNIV program found that "students [and parents] frequently don't know how to navigate campus. Have many signs and provide a map for check-in". Providing directions in an email or via phone call before the event makes the check-in process much smoother. "Make the goals of the camp clear before registration so that the students know what they are walking into.(HS)"

\subsection{Plan Diverse Presentations}

Try to have a wide variety of speakers from every engineering discipline to hold the students' attentions and provide them with a well-rounded experience of the opportunities available. Both programs described a goal of illustrating the different disciplines of engineering, and to do reach this goal, the facilitators noted that it was important to have lots of speakers from different departments, research groups, and experience levels.

\subsection{Engage Students and Parents in Camp Activities}

The high school focused camp facilitator offered advice that focused more on keeping the students' attentions by creating themes and bringing in specific speakers and organizing tasks that relate to the theme. The HS facilitator noted several tricks for organizing the camp:

- Try to schedule the program so that you cover 1-2 engineering majors a day. This will give every day a theme so the students don't feel as if they are jumping from topic to topic.

- Create projects that go along with the theme of the day. 
- Always have smaller projects ready to go if the students end up completing the tasks ahead of time, but also be willing to cut a project if the students end up falling behind schedule.

The high-school focused programs were diverse and therefore required different procedures. For the girl camps, the facilitator tried to book mainly female engineers to give presentations to the students so that they could better identify with the field.

The HS program catered more to the parents perception of the students' experiences. To help the parents understand what is happening in the program, the HS facilitator advises:

Provide notebooks and pencils for notes and sketches. Requiring the students to keep a journal of their activities can be very beneficial as well so that they do not return to their parents saying that they did 'nothing' [and] have the students do final presentations on what they learned for the parents. 'Teaching' the parents what they learned will help to solidify the lessons as well as show the parents what was accomplished during the week.

The HS facilitator emphasized the need to connect with parents of the summer program participants.

\subsection{Provide Outside Entertainment During “Free” Times}

Non-engineering games and off-mode outings provided diversions throughout both programs. 'Shake things up' to increase participation across the board:

- Plan activities for after class at least a month in advance. The students will want to see some of your campus, but they will also want to get out of the dorm. The facilitators took the students to the bowling alley, skating rink, and movie theatre in order to entertain them.(HS)

- If you can afford it, feed them off campus some. Cafeteria food for every meal will eventually become extremely boring.(HS)

- Have lots of board games and impromptu things to do at night. The students have a lot of freedom, but sometimes need encouragement to do things together.(UNIV)

- Engineering games (e.g. legos, k'nex, rube goldberg-like experiments, etc.) would be awesome!(UNIV)

- Weird scavenger hunts are the best! [Assistant] makes really interesting tasks.(UNIV)

- Get students out of their comfort zones a little. They'll bond more.(HS)

When students played games and had fun together, they made friendships that carried over into the classroom and research that enhanced their engineering experiences.

For the UNIV program, although everyone was encouraged to participate in the group activities, attendance was not required. Students were given this option so that they could make their own decisions about participation in small group activities. The UNIV facilitator surveyed provided insight regarding problems with student interactions in small groups:

Don't worry too much if everyone doesn't participate in every game or activity (unless required). Some students don't like Monopoly. If a student continually ostracizes himself, reach out to him and find a way to bring him back in.

It was necessary for the UNIV facilitators to balance the need to empower student participants to make their own decisions with the need to set participation requirements and restrictions. 
Importantly, UNIV facilitators must remember that the student participants are high school students who will soon transition to college freshmen.

\subsection{Stay Engaged During the Camp}

After the camp is planned, it is still important to stay engaged! Even the best-planned programs can have problems; staying involved on a daily basis will allow for quick problem management.

- Check in with the mentors weekly to check students progress and identify issues EARLY!(UNIV)

- Remind your speakers of their dates/times to speak a week in advance as well as the day before. Also provide them information on the number of students and their ages/interests so that they can make their presentations accordingly. (HS)

- Hire experienced camp counselors. I cannot stress the importance of having good staff that can think on their feet as well as handle the students. Sometimes you will need to rely on your counselors to come up with last minute activities or to solve issues without you, you will want people that are quick on their feet and capable.(HS)

- Take a deep breath and handle problems one at a time. Problems will occur, but the program will go on so do not make everything a crisis. Remember why you're doing the camp and have fun with it. (HS)

Both of the undergraduate facilitators stressed the importance of staying engaged with program activities and participants throughout the duration of the summer program.

\subsection{Obtain Feedback from Camp Attendees}

The undergraduate student facilitators noted that student and mentor feedback is a critical component for continued program improvement. Both formative and summative data was useful. For example, for the UNIV program, the end of term suggestions from students were documented and provided to the facilitators to make changes and suggestions for the next year. Both facilitators encourage future undergraduate facilitators to try to implement changes immediately, if applicable. The facilitators offered two strategies for getting immediate feedback from program participants:

- Try to have at least one lunch (maybe several) with the students in the student union or [cafeteria] per week. Then they can tell you about their day, instead of waiting until dinner.(UNIV)

- Engage with the students when you can. Get their perspective on the camp so that you can make changes for the future; plus, you may be surprised at what you learn from them.(HS)

Future undergraduate facilitators should develop a plan for collecting both formative and summative assessment data to drive programmatic improvements.

\section{Conclusion}

In the execution of summer engineering programs, these two facilitators believed that focusing on the development of an engineering identity, the formation of a community, and the recruitment of future engineers is of utmost importance. By focusing on these three ideals, they 
formulated successful programs that helped to educate students while making them more interested in the engineering field.

With regards to the first research question (RQ1: How can undergraduate students effectively facilitate engineering summer programs for K-12 students?), we found that undergraduate student facilitators can be effective mentors for high school students. By focusing on promoting community, developing identity, and recruiting students, the facilitators felt that they were able to achieve the goals of their programs and foster a future in engineering for high school students.

They provided tips and tricks that they believed would make operating these camps easier in the future for other undergraduate facilitators (RQ2: How can the experience for an undergraduate student facilitating engineering summer programs be improved? ). Their main tips were to plan early, provide as much information as possible ahead of time, to have a wide variety of speakers, provide outside entertainment, to stay engaged for quick problem management, and to be open for feedback from the students.

\section{References}

1. Langman, C., Brey, E.M., Zawojewski, J.S. (2014). Designing biomedical engineering summer programs for undergraduates and high school students: A case study of a work-in-progress. Proceedings of the American Society for Engineering Education, 2014

2. Steadman, S.J., Jefferson, G.D., Thomas, T.G., Hsiao, K.T. (2014). Impacting first year engineering retention. Proceedings of the American Society for Engineering Education, 2014.

3. King, K., Myers, B., Sullivan, J., Ennis, T. (2010). Jump starting an engineering future: Engineering summer bridge program meta-analysis of 37 programs. Proceedings of the American Society for Engineering Education, 2010 .

4. Kowalchuk, R., Green, T., Ricks, R., Nicklow, J. (2010). Evaluation of a summer bridge program on engineering students' persistence and success. Proceedings of the American Society for Engineering Education, 2010.

5. Lam, C., Danforth, M., Mehrpouyan, H., Hughes, R. (2014). Summer engineering outreach program for high school students: Survey and analysis. Proceedings of the American Society for Engineering Education, 2014.

6. Papadopoulous, C. \& Reisel, J. (2008). Do students in summer bridge programs successfully improve math placement and persist? A meta-analysis. Proceedings of the American Society for Engineering Education, 2008.

7. Lee, W.C., Seimetz, C. N., \& Amelink, C.T. (2014). Examining the transition to engineering: A multi-case study of six diverse summer bridge program participants. Proceedings of the American Society for Engineering Education, 2014.

8. Ellis. C., Adams, T. E., Bochner, A. P. (2011). Autoethnography: An overview. Forum Qualitative Sozialforschung / Forum: Qualitative Social Research, 12(1), Art. 10, http://nbn-resolving.de/urn:nbn:de:0114-fqs1101108. 
9. Louis, R.A., Mohammadi-Aragh, M.J., \& Lee, W.C. (2012). "Wait...there's a Ph.D. in Engineering Education?" The First Year Experience of Three Students in an Engineering Education Department. Proceedings of the 2012 ASEE Southeast Section Conference, April, 2012.

10. Bruce, J. W. and L. Bruce, “This Town Ain’t Big Enough for the Both of Us: Two Engineering Educator Careers, One Department," Proceedings of the American Society for Engineering Education, 2005.

11. Bruce, L. and J. W. Bruce, "Maximizing Your Productivity as a Junior Faculty Member: Balancing Research, Teaching, and Service," Proceedings of the American Society for Engineering Education, 2004.

12. Bruce, J. W. and L. Bruce, "Maximizing Your Productivity as a Junior Faculty Member: Being Effective in the Classroom," Proceedings of the American Society for Engineering Education, 2004.

13. Strauss, A., and Corbin, J. "Open Coding”. Basics of Qualitative Research: Techniques and Procedures for Developing Grounded Theory, Second Edition, 1998. 